\title{
A CROSS-CULTURAL COMPARISON BETWEEN AMERICANS AND CHINESE IN THEIR ATTITUDES TOWARDS INFORMATION ETHICS
}

\author{
Xin Liu, University of San Diego, xliu@sandiego.edu \\ Yishan Chen, Sichuan Finance and Economics Vocational College, az8205@163.com
}

\begin{abstract}
The purpose of this study is twofold: first to explore cross-cultural differences between American and Chinese business students with respect to their attitudes towards information ethics; and second to investigate the association between their ethical evaluations of the target act and their morality judgments of the target actor in the questionable information-handling issues. Using a sample of 105 American business students and 98 Chinese business students, this study found that the Chinese students tended to be more ethical in the questionable privacy and access issues, whereas their American counterparts were more likely to be ethical in the questionable property issue. In addition, the female students, regardless of their culture backgrounds, were more ethical than the male students. The results further revealed that the students' ethical evaluations of the target act were significantly related to their morality judgments of the target actor. Implications for practitioners, educators, and researchers are discussed.
\end{abstract}

Keywords: Information Technology (IT), Ethics, Culture, Gender

\section{INTRODUCTION}

Information ethics is important for multinational companies that have globalized operations [10]. Despite the vital role of information ethics in the current globalized economy [29], the cross-cultural studies with regard to information ethics are still rare [36].

This paper extends the field of information ethics research by exploring cross-cultural differences between American and Chinese business students in their attitudes towards four common information ethics issues (i.e., privacy, property, accuracy, and access issue). Using a sample of 198 business students from two countries, we found that American and Chinese students differed in their ethical attitudes towards the questionable privacy, property, and access issues. The results further revealed, overall, females were more ethical than males. In addition, participants' ethical evaluations of the target act were highly related to their morality judgments of the target actor in the information ethics issues.

The findings of this study provide significant insights to interested parties such as practitioners, educators, and researchers. One of the most prevalent business ethics issues in the current network-based society is to enhance our understanding of information ethics [2,11]. Understanding the ethical attitudes of employees with different cultural backgrounds is particularly important to multinational companies that attempt to prevent employees' unethical information-handling behavior. The findings of this study may help multinational companies to set localized moral training programs and policies that are suitable to a specific culture [5].

The results of this study may shed lights on the potential focus of information ethics education. The growing concerns over information ethics require increased attention in the ethical education of business students. Several business programs in the United States and China have incorporated information ethics into their business curriculum [4]. The findings of this paper may provide valuable information for business programs in enhancing the ethical education of their students.

Finally, this paper contributes to previous research on information ethics by distinguishing the ethical attitudes towards the target act versus the target actor in the questionable information-handling issues. Despite significant research [14, 16, 23, 36], previous research has not generally explored cross-cultural differences with regard to 


\section{Issues in Information Systems}

Volume 13, Issue 1, pp. 59-67, 2012

employees' attitudes towards information ethics. This paper adds new evidence on the cross-cultural studies in the field of information ethics.

The remainder of this paper consists of four sections. The first section reviews the existing literature on information ethics and generates the research questions. The second section describes the methodology. The third section presents the results. The final section concludes this study by discussing the implications and providing suggestions for future research.

\section{LITERATURE REVIEW}

\section{Information Ethics}

Information-related ethical issues and dilemmas arise whenever users utilize information, information technologies, and information systems [19]. Mason [27] has proposed four basic information ethics issues - privacy, property, accuracy, and access. These four issues are the fundamental issues of information ethics [34] and have long been the main concern in prior research [1, 10, 21, 39].

According to Mason [27], privacy issues arise whenever one's personal or associated information is revealed to others. The improper acquisition and distribution of personal information by organizations is perceived to be unethical [20]. The role of the end-user is very critical in protecting information privacy [16, 20].

Property issues reflect the ownership and property rights of the information [27]. Piracy is one of the most frequently investigated property issues in prior research [31, 39]. Reproducing and sharing another person's intellectual property is viewed as unethical.

Accuracy issues are concerned with the responsibility for the authenticity, fidelity, and accuracy of information [27]. Ethical issues emerge when users rely on the inaccurate results of an information system [12]. Mason [27] focused on the innocent use of incorrect information and suggested that it is the IT provider's responsibility to ensure information accuracy. Very little research [10] has been conducted on information accuracy.

Access issues regard the rights to obtain access or the privileges of access to specific information. The large amount of information currently being managed over the Internet has raised specific concerns about information accessibility [11]. Legal restrictions around the accessibility of information are necessary to protect information privacy [21, 32].

\section{Culture}

Culture is defined as "a collective programming of the mind which distinguishes one category of people from another" [15]. There is extensive research evidence regarding the impact of culture on ethical evaluations [22]. For example, researchers have consistently found cross-cultural differences between Australia and China in auditors' ethical reasoning [35] as well as between Canada and China in ethical attitudes [9] and moral decisions [13].

Information ethics in China is a young academic field, and few studies have examined cross-cultural differences in this field [8]. For example, Eining and Lee [10] utilized Mason's four information ethics issues and found significant cultural differences in the overall acceptance of the property and access issues between U.S. and three distinct Chinese cultures (i.e., Mainland China, Hong Kong, and Taiwan). These four groups showed similar acceptance of the privacy and accuracy issues. Martinsons and So [26], however, found that the ethical assessments of Mason's four information ethics issues between U.S. and Chinese managers were fairly similar, but the processes used in their ethical assessments were significantly different. The results from above two studies were mixed with regard to information ethics. It is necessary to revisit the effect of culture on participants' attitudes towards Mason's four information ethics issues. 


\section{Issues in Information Systems}

Volume 13, Issue 1, pp. 59-67, 2012

Furthermore, the above two studies have mainly focused on the ethical evaluations of the target act, but have not explicitly investigated the morality judgments of the target actor. Cohen, Pant, and Sharp [6] have posited that it is also important to examine the morality of the target person in the ethical studies. For example, Nair and Kamalanabhan [29] have found that both the mortality judgments of the target person and the ethical evaluations of the target action were significantly associated with the ethical decision-making of consumers in the purchase of pirated software. Furthermore, Wong-on-Wing and and Lui [37] have found that the punitive decisions to the target person were significantly associated with the morality judgment of the target person. Based on the foregoing discussions, we proposed the following hypotheses.

$\mathrm{H}_{1 \mathrm{a}}$ : American and Chinese business students will differ in their ethical evaluations of the target act in Mason's four information ethics issues.

$\mathrm{H}_{1 \mathrm{~b}}$ : American and Chinese business students will differ in their morality judgments of the target actor in Mason's four information ethics issues.

\section{Gender Difference}

Several studies have examined gender as a significant factor in the determination of ethical evaluations [28]. In the context of information ethics, females were found to be more ethical as they were less likely to involve in software piracy [38] and more likely to perceive questionable IT behaviors as unethical [18].

Very little research has explored gender differences in business ethics in China and reported mixed findings. For example, Dunn and shome [9] did not find the impact of gender on ethical evaluations in both Canadian and Chinese samples. Ma [24] found gender differences in the Canadian sample, but not in the Chinese sample. Roxas and Stoneback [33] investigated gender differences across eight countries and found that, overall, males were less ethical than females, but Chinese females were less likely to behave ethically. Roxas and Stoneback [33] further encourage more cross-cultural research to be conducted to gain a better understanding of gender differences.

The above studies suggest that the relationship between gender and ethics is still unclear cross-culturally and that more research is needed. Therefore, this paper attempts to explore the impact of gender in the context of information ethics. Based on the above discussions, we proposed the following hypotheses.

$\mathrm{H}_{2 \mathrm{a}}$ : Female students will be more likely to evaluate the target act in Mason's four information ethics issues as unethical than male students.

$\mathrm{H}_{2 \mathrm{~b}}$ : Female students will be more likely to judge the target actor in Mason's four information ethics issues as immoral than male students.

\section{Ethical Attitudes}

This paper further investigates how participants' ethical evaluations of the target act are related to their ethical judgments of the target actor with respect to Mason's four information ethics issues. According to the above discussions, it is predicted that participants' morality judgments of the target actor are significantly related to their ethical evaluations of the target act in Mason's four information ethics issues. Thus, we proposed the following hypothesis.

$\mathrm{H}_{3}$ : There will be a significant association between participants' ethical evaluations of the target act and their morality judgments of the target actor in Mason's four information ethics issues. 


\section{Issues in Information Systems}

Volume 13, Issue 1, pp. 59-67, 2012

\section{RESEARCH METHODOLOGY}

\section{Instrument}

This study utilized the four information ethics scenarios (i.e. privacy, property, accuracy, and access) from Eining and Lee [10]. All participants read the information regarding these four scenarios and responded to the questions at the end of each scenario. Finally, the participants were required to report their age, gender, and other demographic information. Following Wong-on-Wing and Lui [37], the participants were first asked to judge the morality of the target actor after reviewing each scenario on a 7-point scale that ranged from 1 (very immoral) to 7 (very moral); on this scale, higher scores indicate that the target actor is perceived as having a higher level of morality. Following Cohen et al. [6], the participants were then required to provide an overall evaluation of the ethicality of the target act on a 7-point scale that ranged from 1 (ethical) to 7 (unethical). This scale was reverse-coded, and higher scores indicate that the described action is perceived as more unethical. The instrument was originally written in English. After translating it into Chinese, it was back translated into English following Brislin [3] to ensure reliability and equivalence. Two bilingual graduate students in China reviewed the instrument. There were no significant problems in either the translation or back translation.

\section{Participants}

Overall, 105 business students (41 females and 59 males) from the U.S. and 98 business students (64 females and 34 males) from China participated in the study. The average age of the American and Chinese students was 21.1 and 20.7, respectively. The average working experience of the American and Chinese students was 0.3 and 0.34 years, respectively. There were no significant differences in age $(p=0.16)$ and working experience $(p=0.83)$ between the American and Chinese students. Participation in this study was voluntary, and the anonymity of responses was ensured.

\section{RESULTS}

Table 1 shows the correlations between measured variables. Results from Table 1 indicate that there was no statistically significant impact of any demographic characteristics (i.e., age, years of working experience) on participants' ethical evaluations and morality judgments. There were two missing values on participants' responses to their morality judgments. The results were not significantly different by excluding these two observations. Thus, these two observations were included in the following data analyses.

Table 1. Correlations Matrix Among Variables

\begin{tabular}{|c|l|c|c|c|c|c|}
\hline & \multicolumn{1}{|c|}{ Variables } & $\mathbf{1}$ & $\mathbf{2}$ & $\mathbf{3}$ & $\mathbf{4}$ & $\mathbf{5}$ \\
\hline 1 & Culture & 1 & & & & \\
\hline 2 & Gender & $-0.243^{* *}$ & 1 & & & \\
\hline 3 & Age & -0.100 & $0.264^{* * *}$ & 1 & & \\
\hline 4 & Work Experience & 0.016 & 0.101 & $0.714^{* * *}$ & 1 & 1 \\
\hline 5 & Ethical Evaluation & $0.154^{*}$ & $-0.269^{* * *}$ & -0.085 & -0.069 & 0.064 \\
\hline 6 & Morality Judgment & $-0.193^{* *}$ & $0.280^{* * *}$ & 0.135 & $-0.550^{* * *}$ \\
\hline
\end{tabular}

To test the hypotheses, the analysis of variance (ANOVA) was performed to compare the ethical evaluations of the target act with culture and gender as independent variables. The results in Table 2 and Table 3 reveal a statistically significant difference based on culture for the property and access issues. Specifically, the Chinese students were significantly $(p<0.001)$ more likely to evaluate the target act as unethical in the access issue; the American students, on the other hand, tended to view the target act as significantly $(p<0.001)$ more unethical in the property issue. There was no statistical difference between the two groups in the accuracy issue $(p=0.374)$ and a marginally significant difference in the privacy issue $(p=0.053)$. 


\section{Issues in Information Systems}

Volume 13, Issue 1, pp. 59-67, 2012

Table 2. Mean (Standard Deviation) for the Ethical Evaluations of the Target Act

\begin{tabular}{|l|c|c|c|}
\hline & U.S. & China & Total \\
\hline Panel A: Privacy & & & \\
\hline Female & $3.07(1.29)$ & $4.00(2.18)$ & $3.62(1.92)$ \\
\hline Male & $3.36(1.76)$ & $3.50(2.05)$ & $3.41(1.85)$ \\
\hline Total & $3.25(1.59)$ & $3.82(2.14)$ & $3.52(1.88)$ \\
\hline Panel B: Property & & & \\
\hline Female & $3.78(1.49)$ & $2.44(1.62)$ & $2.99(1.70)$ \\
\hline Male & $2.92(1.66)$ & $2.09(1.50)$ & $2.63(1.65)$ \\
\hline Total & $3.26(1.65)$ & $2.31(1.58)$ & $2.81(1.68)$ \\
\hline Panel C: Accuracy & & & \\
\hline Female & $5.00(1.99)$ & $5.07(2.12)$ & $5.04(2.05)$ \\
\hline Male & $4.30(1.96)$ & $4.76(2.16)$ & $4.46(2.03)$ \\
\hline Total & $4.57(1.99)$ & $4.96(2.13)$ & $4.75(2.06)$ \\
\hline Panel D: Access & & & \\
\hline Female & $5.20(1.14)$ & $6.07(1.01)$ & $5.71(1.15)$ \\
\hline Male & $4.27(1.48)$ & $5.50(1.48)$ & $4.69(1.59)$ \\
\hline Total & $4.63(1.43)$ & $5.86(1.23)$ & $5.21(1.47)$ \\
\hline
\end{tabular}

Table 3. ANOVA Results on the Ethical Evaluations of the Target Act

\begin{tabular}{|l|c|c|c|c|c|}
\hline & Df & $\begin{array}{c}\text { Sum of } \\
\text { Squares }\end{array}$ & $\begin{array}{c}\text { Mean } \\
\text { Square }\end{array}$ & F-Value & $\begin{array}{c}p \text {-Value } \\
\text { (Two-Tailed) }\end{array}$ \\
\hline Panel A: Privacy & & & & & \\
\hline Culture & 1 & 13.192 & 13.192 & 3.786 & 0.053 \\
\hline Gender & 1 & 0.529 & 0.529 & 0.152 & 0.697 \\
\hline Culture $\times$ Gender & 1 & 7.156 & 7.156 & 2.054 & 0.153 \\
\hline Error & 194 & 676.015 & 3.485 & & \\
\hline Panel B: Property & & & & & \\
\hline Culture & 1 & 54.690 & 54.690 & 21.612 & $<0.001$ \\
\hline Gender & 1 & 16.980 & 16.980 & 6.710 & 0.010 \\
\hline Culture $\times$ Gender & 1 & 2.966 & 2.966 & 1.172 & 0.280 \\
\hline Error & 194 & 490.911 & 2.530 & & \\
\hline Panel C: Accuracy & & & & & \\
\hline Culture & 1 & 3.321 & 3.321 & 0.792 & 0.374 \\
\hline Gender & 1 & 11.722 & 11.722 & 2.796 & 0.096 \\
\hline Culture $\times$ Gender & 1 & 1.853 & 1.853 & 0.442 & 0.507 \\
\hline Error & 194 & 813.206 & 4.192 & & \\
\hline Panel D: Access & & & & & \\
\hline Culture & 1 & 51.399 & 51.399 & 30.857 & $<0.001$ \\
\hline Gender & 1 & 25.955 & 25.955 & 15.582 & $<0.001$ \\
\hline Culture $\times$ Gender & 1 & 1.515 & 1.515 & 0.909 & 0.341 \\
\hline Error & 194 & 323.152 & 1.666 & & \\
\hline
\end{tabular}




\section{Issues in Information Systems}

Volume 13, Issue 1, pp. 59-67, 2012

Table 4. Mean (Standard Deviation) for the Morality Judgments of the Target Actor

\begin{tabular}{|l|c|c|c|}
\hline & U.S. & China & Total \\
\hline Panel A: Privacy & & & \\
\hline Female & $5.02(1.11)$ & $3.90(1.95)$ & $4.36(1.74)$ \\
\hline Male & $4.74(1.58)$ & $4.32(1.75)$ & $4.59(1.65)$ \\
\hline Total & $4.85(1.41)$ & $4.05(1.88)$ & $4.47(1.70)$ \\
\hline Panel B: Property & & & \\
\hline Female & $4.22(1.59)$ & $5.12(1.71)$ & $4.75(1.71)$ \\
\hline Male & $5.00(1.49)$ & $5.62(1.35)$ & $5.22(1.47)$ \\
\hline Total & $4.69(1.57)$ & $5.30(1.60)$ & $4.98(1.61)$ \\
\hline Panel C: Accuracy & & & \\
\hline Female & $3.02(1.80)$ & $3.00(1.96)$ & $3.01(1.88)$ \\
\hline Male & $3.79(1.70)$ & $3.62(2.10)$ & $3.73(1.84)$ \\
\hline Total & $3.49(1.77)$ & $3.23(2.02)$ & $3.36(1.89)$ \\
\hline Panel D: Access & & & \\
\hline Female & $3.76(0.94)$ & $2.68(1.73)$ & $3.12(1.55)$ \\
\hline Male & $3.92(1.28)$ & $3.32(1.80)$ & $3.71(1.51)$ \\
\hline Total & $3.85(1.16)$ & $2.91(1.77)$ & $3.41(1.55)$ \\
\hline
\end{tabular}

Table 5. ANOVA Results on the Morality Judgments of the Target Actor

\begin{tabular}{|l|c|c|c|c|c|}
\hline & Df & $\begin{array}{c}\text { Sum of } \\
\text { Squares }\end{array}$ & $\begin{array}{c}\text { Mean } \\
\text { Square }\end{array}$ & F-Value & $\begin{array}{c}p \text {-Value } \\
\text { (Two-Tailed) }\end{array}$ \\
\hline Panel A: Privacy & & & & & \\
\hline Culture & 1 & 27.457 & 27.457 & 10.067 & 0.002 \\
\hline Gender & 1 & 0.235 & 0.235 & 0.086 & 0.770 \\
\hline Culture $\times$ Gender & 1 & 5.764 & 5.764 & 2.113 & 0.148 \\
\hline Error & 192 & 523.678 & 2.727 & & \\
\hline Panel B: Property & & & & & \\
\hline Culture & 1 & 26.480 & 26.480 & 10.882 & 0.001 \\
\hline Gender & 1 & 18.843 & 18.843 & 7.743 & 0.006 \\
\hline Culture $\times$ Gender & 1 & 0.912 & 0.912 & 0.375 & 0.541 \\
\hline Error & 192 & 467.223 & 2.433 & & \\
\hline Panel C: Accuracy & & & & & \\
\hline Culture & 1 & 0.447 & 0.447 & 0.127 & 0.721 \\
\hline Gender & 1 & 22.034 & 22.034 & 6.283 & 0.013 \\
\hline Culture $\times$ Gender & 1 & 0.253 & 0.253 & 0.072 & 0.788 \\
\hline Error & 192 & 673.279 & 3.507 & & \\
\hline Panel D: Access & & & & & \\
\hline Culture & 1 & 32.253 & 32.253 & 14.869 & $<0.001$ \\
\hline Gender & 1 & 7.530 & 7.530 & 3.471 & 0.064 \\
\hline Culture $\times$ Gender & 1 & 2.677 & 2.677 & 1.234 & 0.268 \\
\hline Error & 192 & 416.480 & 2.169 & & \\
\hline & & & & & \\
\hline
\end{tabular}

Further, ANOVA was performed to compare the morality judgments of the target actor with culture and gender as independent variables. The results in Table 4 and Table 5 reveal a statistically significant difference based on culture 


\section{Issues in Information Systems}

Volume 13, Issue 1, pp. 59-67, 2012

for the privacy, property, and access issues. Specifically, the Chinese students were significantly more likely to judge that the target actor had a lower level of morality in the privacy issue $(p=0.002)$ and access issue $(p<0.001)$. In contrast, the American students tended to judge that the target actor had a significantly lower level of morality in the property issue $(p=0.001)$. There was no statistically significant difference between the two groups with respect to the accuracy issue $(p=0.721)$. Taken together, the above results supported $\mathrm{H}_{1 \mathrm{a}}$ in the property and access issues, and supported $\mathrm{H}_{1 \mathrm{~b}}$ in the privacy, property, and access issues.

Table 3 and Table 5 also report a statistically significant influence of gender on participants' attitudes towards information ethics. Specifically, the female students were significantly more likely to view the target act as unethical than the male students in the property $(p=0.01)$ and access $(p<0.001)$ issues. Similarly, the female students were significantly more likely to judge the target person as having a lower level of morality in the property $(p=0.006)$ and accuracy $(p=0.013)$ issues. Taken together, the above results supported $\mathrm{H}_{2 \mathrm{a}}$ in the property and access issues, and supported $\mathrm{H}_{2 \mathrm{~b}}$ in the property and accuracy issues.

As showed in Table 1, the morality judgments of the target actor were significantly correlated with the ethical evaluations of the target act across all four scenarios. The correlation coefficient was negative because the measure of participants' ethical evaluations was reverse-coded. This result supported $\mathrm{H}_{3}$, suggesting that participants' morality judgments of the target actor were highly related to their ethical evaluations of the target act.

\section{CONCLUSIONS}

The results of this study suggest that Chinese and American students differ significantly in their responses to the property and access issues. These findings are consistent with the belief that Chinese moral principles are originated from Confucianism that is oriented to an innate morality to maintain harmony in social relationships and organizations. The consideration of universal harmony asserts that certain behaviors may be ethically more acceptable if they maximize overall utilities of the society. Consistently, we found that Chinese students were found to be more tolerant with an unethical property issue since the doctrine of social harmony emphasizes sharing within groups and society. In contrast, an unauthorized access to organizations' resources was perceived as more unethical to Chinese students because it harms overall values of the organization. These findings also confirm the Hofstede's dimension that Chinese people are more collectivism-oriented in making their ethical assessments.

This study has both practical and theoretical implications. First, this study can provide important insights to IT professionals in multinational companies that have globalized operations. The results suggest that common unethical information-handling issues are viewed with some level of opposition. As a result, multinational companies can be confident that a baseline of morality with respect to information ethics exists among their new and future employees. Although students opposed all of the four unethical behaviors to some extent, the results indicated that students have potentials to violate information ethics. Further, globalized organizations should not only emphasize information authorization, but should also consider the potential impact of cultural differences on ethical behaviors. Specifically, IT practitioners should consider proper control systems to monitor information access in the U.S. and improve the understanding of property rights in China.

Second, this finding provides an important insight into the focus of information education. Because the current educational system is flawed, teaching ethical knowledge alone is not sufficient to ensure further effective ethical practices [22]. Understanding these determinants of information ethics decisions can equip students to deal with unethical information-handling issues in a globalized world.

Finally, although researchers have begun to explore information ethics in China, the research in this field is relatively young [8]. This study contributes to business ethics literature by providing more research evidences in the filed of cross-cultural studies. Future studies could also explore cross-cultural differences on other information ethics issues such as conflict of interest, integrity, personal conduct, and social responsibility [7, 17]. 


\section{Issues in Information Systems}

Volume 13, Issue 1, pp. 59-67, 2012

This study has some limitations and thus presents several opportunities for future research. This study has been unable to capture the actual behaviors of the participants because four hypothetical scenarios have been utilized to elicit participants' behavioral intentions. Although prior research has employed the similar approach to explore ethical decision-making [10], this approach does not simulate the same pressure that the participants may experience in an actual environment. Future research could investigate the actual behaviors of people who have experienced similar situations. Moreover, This study used a convenient sample rather than a sample that was randomly selected. It is possible that the students who responded were not representative of the population. A lager sample could greatly enhance the generalizability of the findings. Future research could also explore potential mechanisms or actions that companies could undertake to enhance information ethics.

\section{REFERENCES}

1. Angst, C. (2009). Protect my privacy or support the common-good? Ethical questions about electronic health information exchanges. Journal of Business Ethics, 90, 169-178.

2. Argandoña, A. (2003). The new economy: Ethical issues. Journal of Business Ethics, 44(1), 3-22.

3. Brislin, R. W. (1970). Back-translation for cross-cultural research. Journal of Cross-Cultural Psychology, 1, 185-216.

4. Carbo, T., \& Smith, M. M. (2008). Global information ethics: Intercultural perspectives on past and future research. Journal of the American Society for Information Science \& Technology, 59(7), 1111-1123.

5. Cisco Systems. (2008). Data leakage worldwide: Common risks and mistakes employees make. San Jose, CA: Cisco Systems Inc.

6. Cohen, J. R., Pant, L. W., \& Sharp, D. J. (1996). Measuring the ethical awareness and ethical orientation of Canadian auditors. Behavioral Research in Accounting, 8, 98-119.

7. Conger, S., Loch, K. D., \& Helft B. L. (1995). Ethics and information technology use: A factor analysis of attitudes to computer use. Information Systems Journal, 5(3), 161-183.

8. Davison, R., Sia, S. K., \& Dong, X. Y. (2008). Introduction to the special issue on information systems in China. Information Systems Journal, 18, 325-330.

9. Dunn, P., \& Shome, A. (2009). Cultural crossvergence and social desirability bias: Ethical evaluations by Chinese and Canadian business students. Journal of Business Ethics, 85, 527-543.

10. Eining, M. M., \& Lee, G. M. (1997). Information ethics: An exploratory study from an international perspective. Journal of Information Systems, 11(1), 1-17.

11. Floridi, L. (2009). Network ethics: Information and business ethics in a networked society. Journal of Business Ethics, 90, 649-659.

12. Forester, T., \& Morrison, P. (1990). Computer Ethics: Cautionary Tales and Ethical Dilemmas in Computing. Cambridge, MA: The MIT Press.

13. Ge, L., \& Thomas, S. (2008). A cross-cultural comparison of the deliberative reasoning of Canadian and Chinese accounting students. Journal of Business Ethics, 82(1), 189-211.

14. Hilton, T. (2000). Information systems ethics: A practitioner survey. Journal of Business Ethics, 28(4), 279284.

15. Hofstede, G. (1980). Culture's consequences: International differences in work-related values. Beverly Hills, CA: Sage Publishing.

16. Hsu, M. -H., \& Kuo, F. -Y. (2003). The effect of organization-based self-esteem and deindividuation in protecting personal information privacy. Journal of Business Ethics, 42(4), 305-320.

17. Khazanchi, D. (1995). Unethical behavior in information systems: The gender factor. Journal of Business Ethics, 14(9), 741-749.

18. Krete, J., \& Cronan, T. (1998). How men and women view ethics. Communications of the ACM, 41(9), 70-76.

19. Kuo, F. -Y., \& Hsu, M. -H. (2001). Development and validation of ethical computer self-efficacy measure: The case of softlifting. Journal of Business Ethics, 32(4), 299-315.

20. Kuo, F. -Y., Lin, C., \& Hsu, M. -H. (2007). Assessing gender differences in computer professionals' selfregulatory efficacy concerning information privacy practices, Journal of Business Ethics, 73(2), 145-160.

21. Lam, H., \& Harcourt, M. (2003). The use of criminal record in employment decisions: The rights of exoffenders, employers and the public. Journal of Business Ethics, 47, 237-252. 


\section{Issues in Information Systems}

Volume 13, Issue 1, pp. 59-67, 2012

22. Lam, K. -C., \& Shi, G. (2008). Factors affecting ethical attitudes in Mainland China and Hong Kong. Journal of Business Ethics, 77(4), 463-479.

23. Lin, C., \& Ding, C. G. (2003). Modeling information ethics: The joint moderating role of locus of control and job insecurity. Journal of Business Ethics, 48(4), 335-346.

24. Ma, Z. (2010). The SINS in business negotiations: Explore the cross-cultural differences in business ethics between Canada and China. Journal of Business Ethics, 91, 123-135.

25. Martinsons, M. G., \& Ma, D. (2009). Sub-cultural differences in information ethics across China: Focus on Chinese management generation gaps. Journal of the Association for Information Systems, 10, 816-833.

26. Martinsons, M. G., \& So, S. K. K. (2005). International differences in information ethics. Proceedings of the Academy of Management Conference. Honolulu, Hawaii.

27. Mason, R. (1986). Four ethical issues of the information age. MIS Quarterly, 10, 5-12.

28. McCabe, A., Ingram, R., \& Dato-on, M. (2006). The business of ethics and gender. Journal of Business Ethics, 64(2), 101-116.

29. Mingers, J., \& Walsham, G. (2010). Toward ethical information systems: The contribution of discourse ethics. MIS Quarterly, 34(4), 833-854.

30. Nair, P., \& Kamalanabhan, T. J. (2010). Factors influencing consumer ethical decision making of purchasing pirated software: Structural equation modeling on Malaysian consumer. Journal of International Business Ethics, 3(1), 30-40.

31. Peslak, A. R. (2005). An ethical exploration of privacy and radio frequency Identification. Journal of Business Ethics, 59(4), 327-345.

32. Rosen, C. M., \& Carr G. M. (1997). Fares and free riders on the information highway. Journal of Business Ethics, 16(12/13), 1439-1445.

33. Roxas, M. L., \& Stoneback, J. Y. (2004). The importance of gender across cultures in ethical decision-making. Journal of Business Ethics, 50(2), 149-165.

34. Severson, R. J. (1997). The principles of information ethics. Armonk, New York: M. E. Sharpe.

35. Tsui, J., \& Windsor, C. (2001). Some cross-cultural evidence on ethical reasoning. Journal of Business Ethics, 31(2): 143-151.

36. Walstrom, K. A., (2006). Social and legal impacts on informaiton ethics decision making. Journal of Computer Information Systems, 47(2), 1-8.

37. Wong-on-Wing, B., \& Lui, G. (2007). Culture, implicit theories and the attribution of morality. Behavioral Research in Accounting, 1(19), 231-246.

38. Wood, W., \& Glass, R. (1995). Sex as a determinant of software piracy. Journal of Computer Information System, 36(2), 37-43.

39. Zamoon, S., \& Curley, S. (2008). Ripped from the headlines: What can the popular press teach us about software piracy? Journal of Business Ethics, 83(3), 515-533. 